Inken Schmidt-Voges, Mikropolitiken des Friedens. Semantiken und Praktiken des Hausfriedens im 18. Jahrhundert

Berlin/Boston : de Gruyter-Oldenbourg (bibliothek altes Reich, 18), 2015, IX, 370 p., 79,90€.

Jochen Hoock

\title{
CpenEdition
}

Journals

Édition électronique

URL : http://journals.openedition.org/ifha/8384

DOI : $10.4000 /$ ifha. 8384

ISSN : 2198-8943

Éditeur

IFRA - Institut franco-allemand (sciences historiques et sociales)

Référence électronique

Jochen Hoock, « Inken Schmidt-Voges, Mikropolitiken des Friedens. Semantiken und Praktiken des Hausfriedens im 18. Jahrhundert ", Revue de l'IFHA [En ligne], Date de recension, mis en ligne le 01 février 2016, consulté le 22 septembre 2020. URL : http://journals.openedition.org/ifha/8384 ; DOI : https://doi.org/10.4000/ifha.8384

Ce document a été généré automatiquement le 22 septembre 2020.

(CIFHA 


\section{Inken Schmidt-Voges, Mikropolitiken des Friedens. Semantiken und Praktiken des Hausfriedens im 18. Jahrhundert}

Berlin/Boston : de Gruyter-Oldenbourg (bibliothek altes Reich, 18), 2015, IX, 370 p., 79,90€.

Jochen Hoock

Les rapports entre "paix domestique » et " paix civile » furent au début du XIXe siècle un des thèmes de la pensée conservatrice qui a longtemps dominé la sociologie de la famille avec les travaux de Frédéric Le Play en France et Wilhelm Heinrich Riehl en Allemagne. L'enquête d'Inken Schmidt-Voges tourne résolument le dos à cette tradition en abordant les pratiques sociales et leurs expressions discursives que la notion du Hausfrieden résume en un seul mot. Le cadre chronologique de l'enquête qui couvre une période allant de la fin du XIV ${ }^{e}$ au début du XIX ${ }^{e}$ siècle signale d'entrée de jeu l'ambition d'une étude qui ne se limite pas, et cela malgré son titre, à la seule analyse du microcosme familial et à son rôle structurant, mais vise bien plus à une "praxéologie de la paix " pas moins ambitieuse que celle qu'envisageait sous ces termes Raymond Aron dans Paix et guerre entre les Nations. C'est en effet en analysant les pratiques, stratégies et représentations subjectives se rapportant à la vie domestique et à ses multiples expressions sociales et politiques que l'enquête tente de dégager les éléments d'une théorie de l'action de la paix au sens le plus global du terme.

Une longue introduction esquisse la problématique associée à la notion de «micropolitique » et les dimensions multiples d'une paix vécue dont il s'agit de saisir les codes et expressions discursives marquant les pratiques et les formes d'interactions observables au fil du temps. En définitive il ne s'agit pas moins que de déchiffrer toute l'étendue du champ conceptuel de la paix allant de la paix de Dieu, de celle de l'âme et celle de la maison commune aux constructions juridiques censées assurer la paix entre les nations et leur ancrage théologique, philosophique et, plus largement, moral. C'est à ce vaste programme que s'attaque le deuxième chapitre retraçant la sémantique discursive de Hausfrieden/paix domestique sur plus de cinq siècles en marquant les 
ruptures sémantiques, qui vont de la paix domestique comme ordre vécu à celle garantie en termes de droit pour finir avec sa « domestication » (Verhäuslichung) dans les revues hebdomadaires morales de la fin du XVIII ${ }^{\mathrm{e}}$ siècle. Ces analyses se fondent sur les traités théologiques et juridiques autant que sur les nombreux manuels pratiques de toute sorte s'attachant à la vie domestique et à la conduite des acteurs divers constituant le ménage traditionnel. Il en résulte l'esquisse d'une grille sémantique qui offre les clefs et les termes pratiques pour la négociation actuelle de la paix entre ces différents partis.

C'est cette actualisation négociée que décrit le troisième chapitre à travers une analyse des conflits domestiques et leur régulation à partir d'une vaste documentation judiciaire offerte par les archives de la ville d'Osnabrück au XVIII ${ }^{\mathrm{e}}$ siècle. Il s'agit pour l'essentiel d'études de cas regroupées sous les rubriques fundamenta pacis, materiae pacis, violationes pacis, negotiationes pacis et remedia pacis qui se lisent comme une anthropologie du fait domestique en acte. À la différence de l'image

traditionnelle de la maison comme cadre statique dont il s'agit de maintenir l'ordre établi, la communauté domestique s'y présente comme l'expression d'un ensemble de pratiques, dont l'existence n'est en définitive assurée que si les bases de rapports entre tous ses membres sont assez stables pour permettre une communication constructive en cas de conflit. La conception de la «paix » qui s'en dégage semble donc se distinguer de ce fait des représentations à d'autres niveaux des sociétés à l'époque moderne dont celui des rapports interétatiques. L'accent mis sur la dimension éthique et les ressorts individuels de la paix sociale laisse penser que son maintien comme son rétablissement est essentiellement conçu comme la résultante d'un processus émanant de comportements collectifs seuls capables d'en assurer le maintien. Que cela ait pu influencer l'action au niveau des États semble tout à fait concevable, tout comme le rôle de la maison dans la société globale relativise, de par les valeurs et normes vécues qui s'y rattachent, l'action structurante des instances étatiques considérées généralement comme décisives pour la formation des sociétés modernes.

L'étude séduit par la richesse de sa documentation et les récits, parfois pittoresques, des conflits observés en milieu urbain. On regrettera cependant que la théorie de la «maison entière » défendue au XXe siècle par Otto Brunner et qui a dominé longtemps l'histoire sociale en Allemagne n'ait guère été discutée plus amplement. Cela vaut aussi pour l'absence de toute référence explicite à Frédéric Le Play et la sociologie de la famille du XIX ${ }^{e}$ siècle qui aurait sans doute permis de préciser la portée spécifique du concept de «micropolitique » et sa place dans l'analyse des pratiques sociales.

Vous trouverez la table des matières ici : http://d-nb.info/1067968725/04.

\section{INDEX}

Index chronologique : Période moderne

Thèmes : Histoire des États et des pouvoirs, Histoire religieuse, Histoire sociale, Histoire du droit, Historiographie/Méthodologie 
AUTEUR

JOCHEN HOOCK

Université Paris 7 - Denis Diderot 